\title{
REVISED DNA interference by a mesophilic Argonaute protein,
}

\section{CbcAgo [version 2; peer review: 2 approved]}

\section{Nieves García-Quintans, Laurie Bowden, José Berenguer (iD, Mario Mencía}

Centro de Biología Molecular Severo Ochoa, Universidad Autónoma de Madrid-Consejo Superior de Investigaciones Científicas, Madrid, Madrid, 28049, Spain

V2 First published: 22 Mar 2019, 8:321

https://doi.org/10.12688/f1000research.18445.1

Latest published: 09 Jan 2020, 8:321

https://doi.org/10.12688/f1000research.18445.2

\section{Abstract}

Background: The search for putative enzymes that can facilitate gene editing has recently focused its attention on Argonaute proteins from prokaryotes (pAgos). Though they are structural homologues of human Argonaute protein, which uses RNA guides to interfere with RNA targets, pAgos use ssDNA guides to identify and, in many cases, cut a complementary DNA target. Thermophilic pAgos from Thermus thermophilus, Pyrococcus furiosus and Methanocaldococcus jasmanii have been identified and thoroughly studied, but their thermoactivity makes them of little use in mesophilic systems such as mammalian cells.

Methods: Here we search for and identify CbcAgo, a prokaryotic Argonaute protein from a mesophilic bacterium, and characterize in vitro its DNA interference activity.

Results: CbcAgo efficiently uses 5'P-ssDNA guides as small as 11-mers to cut ssDNA targets, requires divalent cations (preferentially, $\mathrm{Mn}^{2+}$ ) and has a maximum activity between 37 and $42{ }^{\circ} \mathrm{C}$, remaining active up to $55^{\circ} \mathrm{C}$. Nicking activity on supercoiled dsDNA was shown. However, no efficient double-strand breaking activity could be demonstrated.

Conclusions: CbcAgo can use gDNA guides as small as 11 nucleotides long to cut complementary ssDNA targets at $37^{\circ} \mathrm{C}$, making it a promising starting point for the development of new gene editing tools for mammalian cells.

Keywords

Argonaute, prokaryotic, mesophilic, gene edition, characterization, DNA-DNA interference

\section{Open Peer Review \\ Approval Status \\ 1 2 \\ version 2 \\ (revision) \\ 09 Jan 2020 \\ version 1 \\ 22 Mar 2019

$\begin{array}{cc}\checkmark & \checkmark \\ \text { view } & \text { view } \\ ? & ? \\ ? & \text { view }\end{array}$ \\ 1. Eduardo Santero (iD), Pablo de Olavide University, Seville, Spain \\ Inés Canosa iD, University Pablo de Olavide, Seville, Spain \\ 2. Nathan A. Tanner iD, New England Biolabs, Ipswich, USA \\ Any reports and responses or comments on the article can be found at the end of the article.}


Corresponding authors: José Berenguer (jberenguer@cbm.csic.es), Mario Mencía (mmencia@cbm.csic.es)

Author roles: García-Quintans N: Investigation, Methodology; Bowden L: Investigation; Berenguer J: Funding Acquisition, Supervision, Writing - Original Draft Preparation, Writing - Review \& Editing; Mencía M: Conceptualization, Supervision, Writing - Review \& Editing

Competing interests: No competing interests were disclosed.

Grant information: This work was supported by a grant from the Spanish Ministry of Economy and Competitiveness [BIO2016-77031-R] to J. Berenguer. An institutional grant from Fundación Ramón Areces to the CBMSO is also acknowledged.

The funders had no role in study design, data collection and analysis, decision to publish, or preparation of the manuscript.

Copyright: ( 2020 García-Quintans N et al. This is an open access article distributed under the terms of the Creative Commons Attribution License, which permits unrestricted use, distribution, and reproduction in any medium, provided the original work is properly cited.

How to cite this article: García-Quintans N, Bowden L, Berenguer J and Mencía M. DNA interference by a mesophilic Argonaute protein, CbcAgo [version 2; peer review: 2 approved] F1000Research 2020, 8:321 https://doi.org/10.12688/f1000research.18445.2

First published: 22 Mar 2019, 8:321 https://doi.org/10.12688/f1000research.18445.1 


\section{REVISED Amendments from Version 1}

Most of the changes included in the new version are intended to actualize the article in relation with the already published articles of Hedgge et al. and Kuzmenko et al describing a similar pAgo from other strain from Clostridium butyricum, only one of which (Hedgge et al.) was posted as unrevised article when the first version of this article was sent. Basically, the differences that we reported at the level of thermostability of $\mathrm{CbcAgo}$ in comparison with that of $\mathrm{CbcAgo}$ have been reconsidered once known the results of Kuzmenko et al reporting also a higher thermostability for their tagged version of $\mathrm{CbAgo}$. Other minor changes are related with the proper alignment of the numbering of the figures or an increase in the size of the lettering for an easier reading. The Discussion section has been also modified to provide appropriate answers to the reviewers comments, included in the corresponding section.

Any further responses from the reviewers can be found at the end of the article

\section{Introduction}

Argonaute proteins play a central role in gene silencing and defense against external RNA in eukaryotes, binding small RNA molecules that are then used as guides to scan for complementary RNA targets in the form of mRNAs or RNA viruses. Depending on the presence of specific residues in the protein sequence, the targets can be cut or simply blocked, with degradation carried out by other proteins, leading to inhibition of the expression (silencing) of the genes involved ${ }^{1}$. The structure of eukaryotic Argonaute proteins (eAgo) consists of four domains organized in a specific order (N-PAZ-MID-PIWI) which are each involved in different steps of the protein's enzyme activity.

Homologues to eAgo that contain these four domains are found in both bacteria and archaea, being collectively known as prokaryotic Argonaute (pAgo) proteins. Their function seems to depend on the species, targeting either RNA or DNA ${ }^{2}$. The best studied pAgos, such as those from Thermus thermophilus (ThAgo) ${ }^{3}$, Pyrococcus furiosus (PfAgo) ${ }^{4}$ and Methanocaldococcus jannaschii $(\mathrm{MjAgo})^{5}$, use ssDNA guides (gDNA) to target DNA in vitro, with ThAgo and PfAgo shown to be involved in defense against invading DNA in vivo ${ }^{3,4}$. In contrast, pAgo from Aquifex aeolicus $(\mathrm{AeAgo})^{6}$ and Natronobacterium gregoryi $(\mathrm{NgAgo})^{7}$ use ssDNA guides to target RNA, suggesting a putative role in gene silencing, similar to that of eAgo, or in defense against RNA viruses. Moreover, other pAgos, like that of Rhodobacter spheroides (RsAgo), use RNA guides against DNA targets, maintaining its defense capability against invading DNA despite the absence of endonucleolytic activity in its PIWI domain ${ }^{8}$.

High-resolution structures of pAgos in complex with guide and target DNAs support a mechanism of hydrolysis homologous to that of RNAse H, in which an Asp-Glu-Asp-Asp catalytic tetrad is formed at the cleavage site of its PIWI domain upon scanning and hybridization of gDNA and target ssDNA 9 . However, the actual mechanism for generation of the gDNA in vivo is essentially unknown and the described in vitro capability of the $\mathrm{MjAgo}^{5}$ and ThAgo ${ }^{10}$ apoproteins to cleave dsDNA (named DNA chopping) seems an unlikely mechanism for the generation of gDNA in vivo, as it cannot explain the observed inactivity against its own genomic DNA.
Following description of the mechanism of action of ThAgo and PfAgo, the possibility of using pAgos as tools for gene editing has been proposed, with the advantage of being easier to use than the CRISPR-Cas9 system ${ }^{11}$. However, attempts to directly use ThAgo for gene editing of mammalian cells were unsuccessful, likely due to the thermoactivity of this protein (unpublished results of our laboratory). Publication of gene editing of mammalian cells using NgAgo, a mesophilic pAgo from a hyperhalophilic archaea $^{12}$, sparked controversy due to the inability of many other laboratories to reproduce the results $^{13}$. Other published research has suggested that the substrates for $\mathrm{NgAgo}$ are RNA targets ${ }^{7}$. Despite this, the search has continued for new pAgos that could be successful in gene editing at low temperatures through a DNA-DNA interference mechanism ${ }^{11}$.

At the time of writing this article, an unreviewed preprint article describing the properties and structure of a mesophilic pAgo derived from Clostridium butyricum (CbAgo) was posted online by the group of John van der Oost, immediately followed by an article of the group of Alexei A. Aravind describing biochemically the same CbAgo protein and also an pAgo protein from Limnothrix rosea (LrAgo). Both articles were further published ${ }^{14,15}$. Here we show our independent and contemporary work leading to the identification of a pAgo from the strain CWBI 1009 of C. butyricum (CbcAgo thereafter), describing its properties in comparison to that of the CbAgo protein characterized in these articles, including a requirement for 5'-phosphorylated gDNA and a smaller minimum gDNA size required for full activity.

\section{Methods}

Identification, overproduction and purification of CbcAgo

The search for mesophilic pAgos was performed using the web interface of the BLASTp program, with the protein sequence of Natronobacterium gregoryi (WP_005580376.1) as a query, and directed to non-redundant GenBank CDS translations + PDB + SwissProt + PIR + PRF, excluding environmental samples from WGS projects. Using the default settings, proteins from two strains of Clostridium butyricum were identified (WP_045143632.1 and WP_058142162.1). Further BLASTp and COBALT analysis also with default settings revealed the presence of the four domains that characterize pAgos and the residues required for their likely nuclease activity within the PIWI domain. A fusion gene encoding an N-terminal Strep (II) tag and protein WP_045143632.1 from the strain C. butyricum CWBI1009 (CbcAgo) was synthesized (GenScript) following the codon usage of E. coli and cloned into a pET11d vector (Agilent Technologies) to generate the expression plasmid pET11-CbcAgo. For overexpression in E. coli KRX strain (genotype [F', traD36, $\Delta o m p \mathrm{P}, \operatorname{proA}^{+} \mathrm{B}^{+}, \operatorname{lacI}^{\mathrm{q}}, \Delta($ lac $\left.\mathrm{Z}) \mathrm{M} 15\right] \Delta o m p \mathrm{~T}$, end $\mathrm{A} 1$, rec $\mathrm{A} 1$, gyrA96 $\left(\mathrm{Nal}^{\mathrm{r}}\right)$, thi-1, hsdR17 $\left(\mathrm{r}_{\mathrm{k}}, \mathrm{m}_{\mathrm{k}}^{+}\right), \mathrm{e} 14^{-}\left(\mathrm{McrA}^{-}\right)$, relA1, supE44, $\Delta$ (lac-proAB), $\Delta$ (rhaBAD)::T7 RNA polymerase) (Promega), cultures were grown at $37{ }^{\circ} \mathrm{C}$ in $\mathrm{LB}$ with $100 \mu \mathrm{g} / \mathrm{ml}$ ampicillin until an optical density at $600 \mathrm{~nm}\left(\mathrm{OD}_{600}\right)$ of 0.7 was reached. CbcAgo expression was induced by the addition of $1 \mathrm{mM}$ IPTG (isopropyl $\beta$-D-1-thiogalactopyranoside) and $0.1 \%(\mathrm{w} / \mathrm{v})$ of L-Rhamnose to the growth medium with further incubation at $20{ }^{\circ} \mathrm{C}$ for $18 \mathrm{~h}$ with mild shaking. This procedure resulted in the production of a protein of the expected size $(90.4 \mathrm{kDa}, 794$ 
amino acids), as revealed by SDS-PAGE in comparison with size standards. After lysis by French press in TrisHCl $50 \mathrm{mM}$, $1 \mathrm{M} \mathrm{NaCl}, \mathrm{pH} 8$ buffer and elimination of insoluble debris by centrifugation $\left(30 \mathrm{~min} / 30,000 \times \mathrm{g} / 4{ }^{\circ} \mathrm{C}\right.$ ) and filtration (Acrodisc Syringe Filter $0.45 \mu \mathrm{m}$, Life Sciences), the protein was purified by affinity chromatography in Strep-Tactin sepharose (IBA, Germany, Cat no. 2-1201-010). The CbcAgo protein concentration was measured by comparison with known concentration of BSA in Comassie-Blue stained SDS-PAGE using ImajeJ for quantification. Aliquots were stored at $-20{ }^{\circ} \mathrm{C}$ with $40 \%$ glycerol until use. As a negative control for the interference assays, a double mutant lacking the catalytic tetrad (D541A, E577A) was generated (called DE mutant hereafter) by site-directed mutagenesis, (Quick change II site-directed mutagenesis kit, Agilent Technologies) overexpressed from plasmid pET11-CbcAgoDE and purified in the same way.

Proteins purified by this method were separated in an SDS-PAGE gel, digested with trypsin and chemotrypsin and the resulting peptides were identified by LC-MS/MS in an LTQ Orbitrap Velos Pro (high resolution, short gradient) equipment.
DNA interference assays

The synthetic gDNA and ssDNA targets described in Table 1 (SIGMA-ALDRICH) were used for the interference assays. The standard interference assays were carried out as follows: after pre-incubation of the CbcAgo protein $(6 \mu \mathrm{M})$ with a given primer $(6 \mu \mathrm{M})$, selected among those described in Table 1, for $10 \mathrm{~min}$ at $37{ }^{\circ} \mathrm{C}$ in reaction buffer $(20 \mathrm{mM}$ Tris $\mathrm{HCl}$,

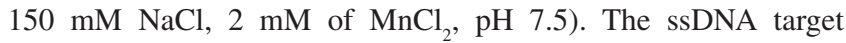
$(1.2 \mu \mathrm{M})$ was added and the samples were incubated in the same buffer for $50 \mathrm{~min}$ at $37{ }^{\circ} \mathrm{C}$, except when otherwise indicated. After incubation, the reaction was stopped by the addition to the sample of one reaction volume of loading buffer (85\% formamide, $10 \mathrm{mM}$ EDTA, $20 \%$ glycerol, $0.05 \%$ bromophenol blue, $0.05 \%$ xylene cyanol) and further heating for $10 \mathrm{~min}$ at $100{ }^{\circ} \mathrm{C}$. Separation of the ssDNA substrate, products and gDNA was carried out by electrophoresis in an 18-20\% polyacrylamide gel in the presence of $6 \mathrm{M}$ urea (U-PAGE), using SYBR Gold Nucleic Acid Gel Stain for staining (Invitrogen S11494) and a UV spectrophotometer for detection. Synthetic oligonucleotides of different sizes were used as mobility standards.

Table 1. Sequence of ssDNA targets and guide DNAs used in this work. Table shows the names and sequence of the two target DNA used in this work (T-45 and T-50) and the oligonucleotides used as gDNA. All the gDNA except for 21-OH and $20-\mathrm{OH}$ are phosphorylated at their 5 ' end, being labelled as [phos].

\begin{tabular}{|c|c|c|}
\hline Name & Sequence $\left(5^{\prime}-3^{\prime}\right)$ & Description \\
\hline $\mathrm{T}-45$ & AAACGACGGCCAGTGCCAAGCTTACTATACAACCTACTACCTCAT & DNA target \\
\hline $\mathrm{T}-50$ & GGTCGCGGAGGTTATGGATGCGATCGCTGCGGCCGATCTTAGCCAGACGA & DNA target \\
\hline $\mathrm{W}-1$ & [phos ]-TGAGGTAGTAGGTTGTATAGT & DNA guide to 1 nt of $3^{\prime}$-target \\
\hline$W-2$ & [phos ] -GAGGTAGTAGGTTGTATAGTA & DNA guide to 2 nt of $3^{\prime}$-target \\
\hline$W-3$ & [phos ] -AGGTAGTAGGTTGTATAGTAA & DNA guide to 3 nt of 3'-target \\
\hline$W-4$ & [phos] -GGTAGTAGGTTGTATAGTAAG & DNA guide to 4 nt of $3^{\prime}$-target \\
\hline$W-5$ & [phos] -GTAGTAGGTTGTATAGTAAGC & DNA guide to 5 nt of $3^{\prime}$-target \\
\hline$W-6$ & [phos ]-TAGTAGGTTGTATAGTAAGCT & DNA guide to 6 nt of $3^{\prime}$-target \\
\hline$W-7$ & [phos] -AGTAGGTTGTATAGTAAGCTT & DNA guide to 7 nt of $3^{\prime}$-target \\
\hline$W-8$ & [phos ]-GTAGGTTGTATAGTAAGCTTG & DNA guide to 8 nt of $3^{\prime}$-target \\
\hline $20-P$ & [phos] GAGGTAGTAGGTTGTATAGT & DNA guide to 2 nt of $3^{\prime}$-target \\
\hline $21-\mathrm{OH}$ & TGAGGTAGTAGGTTGTATAGT & DNA guide to 1 nt of $3^{\prime}$-target \\
\hline $20-\mathrm{OH}$ & GAGGTAGTAGGTTGTATAGT & DNA guide to 2 nt of 3'-target \\
\hline Hy $10-7$ & [phos ] CGTCTGG & 7 nt DNA guide \\
\hline Hy10-9 & [phos] CGTCTGGCT & 9 nt DNA guide \\
\hline Hy10-11 & [phos ] CGTCTGGCTAA & 11 nt DNA guide \\
\hline Hy10-13 & [phos ] CGTCTGGCTAAGA & 13 nt DNA guide \\
\hline Hy10-15 & [phos ] CGTCTGGCTAAGATC & 15 nt DNA guide \\
\hline Hy10-17 & [phos] CGTCTGGCTAAGATCGG & 17 nt DNA guide \\
\hline Hy10-19 & [phos ] CGTCTGGCTAAGATCGGCC & 19 nt DNA guide \\
\hline Hygro-1 & [phos] TGGTCGCGGAGGTTATGGATGCGATCGCT & DNA guide (Fw) \\
\hline Hygro-2 & [phos] TCATCCATAACCTCCGCGACCGGTTGCAG & DNA guide (Rv) \\
\hline Hygro-3 & [phos] GGTCGCGGAGGTTATGGATGCGATCGCT & DNA guide (Fw) \\
\hline Hygro-4 & [phos ] CATCCATAACCTCCGCGACCGGTTGCAG & DNA guide (Rv) \\
\hline
\end{tabular}


Assays of nicking activity on dsDNA were carried out following the above protocol using plasmid pMH184 isolated from E. coli cells in its supercoiled form as target (GenJET Plasmid Miniprep Kit, Thermo scientific, Cat no. K0503). The molar ratio between CbcAgo: guide: dsDNA target was $3: 6: 0.0074(\mu \mathrm{M})$. Reactions were stopped by adding $100 \mu \mathrm{g} / \mathrm{mL}$ of Proteinase $\mathrm{K}$ (Promega) and the products were separated in agarose gels. As mobility standards, linear and nicked forms of pMH184 were generated by digestion with EcoRI (Thermo scientific, FD0275) and Nt.BspQI (Biolabs R06445) restriction enzymes, respectively.

\section{Results}

The Strep II-tagged CbcAgo protein and its inactive DE derivative were overexpressed and purified by affinity chromatography (Figures 1A and 1B). In addition to the wild-type or DE mutant proteins, two smaller proteins were co-purified at low proportions even after repeated cycles of affinity chromatography. Mass spectrometry of proteolytic Trypsin/Chemotrypsin digestion fragments of these recalcitrant contaminant proteins revealed them to be the GroEL chaperone and an N-terminal fragment of the Strep II-tagged CbcAgo proteins (Figure 1C).

A

M T S Sf FT W1 W2 W3 W4 W5 E1 E2 E3 E4 E5

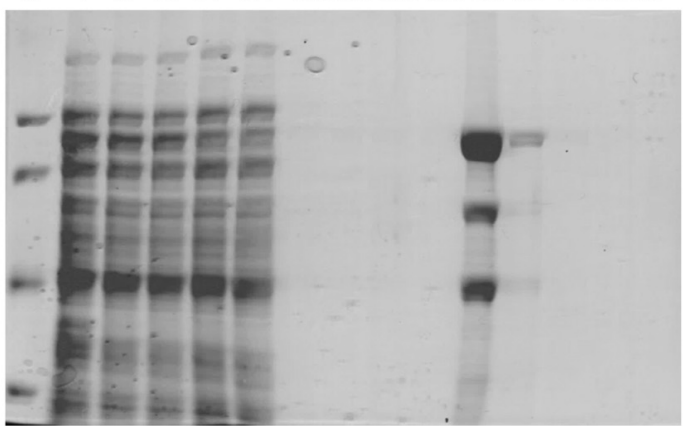

B

$\begin{array}{lllllllllllllllll}M & T & S & \text { Sf } & \text { FT } & \text { W1 W2 } & \text { W3 W4 W5 E1 } & \text { E2 E3 E4 }\end{array}$

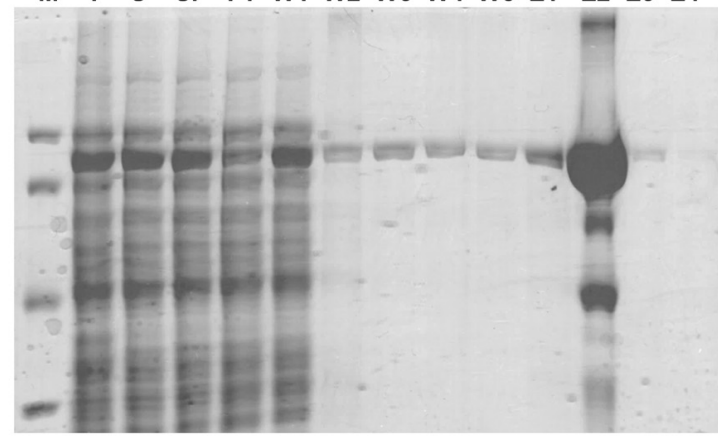

C
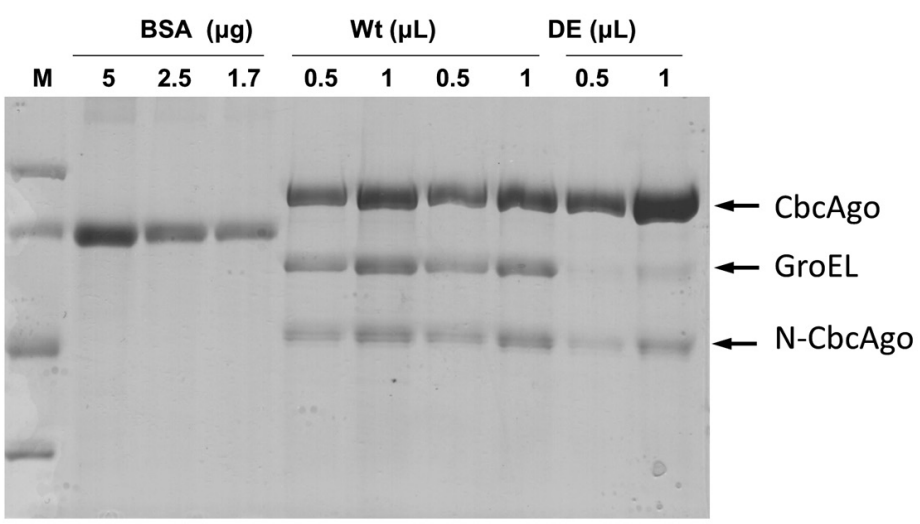

Figure 1. Purification of CbcAgo. Purification by affinity chromatography of $(\mathbf{A})$ wild-type or $(\mathbf{B})$ inactive DE mutant. Lanes: M - molecular weight markers from top to bottom of $97.4,66.2,45$ and $31 \mathrm{kDa}$; $\mathrm{T}$ - total cell protein fraction; $\mathrm{S}$ - soluble fraction; Sf - filtered soluble fraction; FT - flow through; W1-5 - fractions obtained upon addition of washing buffer; E1-5 - fractions obtained upon addition of elution buffer. (C) Protein concentration of two independent preparations of wild-type CbcAgo and a single preparation of the DE mutant, compared with bovine serum albumin as standard (BSA). Protein identification was carried out by proteomic analysis. 
Presence of these co-purified proteins did not interfere with the capacity of the wild-type CbcAgo protein to cleave the ssDNA target after being preloaded with a complementary gDNA guide (Figure 2). As the DE mutant was inactive in these assays, it was concluded that the endonuclease activity detected in the wild type was dependent on the presence of an active endonucleolytic site in CbcAgo's C-terminal PIWI domain and was not as a result of hidden activity of the co-purified proteins.

Optimization of the DNA-DNA interference activity revealed a strict requirement for divalent cations, with higher activity shown in the presence of $\mathrm{Mn}^{2+}$ compared to $\mathrm{Mg}^{2+}$ (Figure 3), and a significant resistance to high ionic strength (Figure 4). Subsequent experiments were carried out with $\mathrm{Mn}^{2+}$ and $150 \mathrm{mM}$ of $\mathrm{NaCl}$ in the interference buffer. Under these conditions, we then analyzed the range of temperatures at which this endonuclease was active, finding significant activity in the range of $25-55^{\circ} \mathrm{C}$, with maximum activity between 37 and $42^{\circ} \mathrm{C}$, as revealed by the absence of the target DNA band at this temperature, and no activity at $60^{\circ} \mathrm{C}$ and above (Figure 5). All subsequent experiments were carried out at $37^{\circ} \mathrm{C}$.

The requirements of the gDNA were also analyzed, clearly showing a need for a 5' phosphate end, as gDNAs with 5'-OH were unable to direct CbcAgo to the complementary ssDNA target (Figure 6). The cutting site in the ssDNA target was also analyzed in detail using two gDNAs (20- and 21-mers) with a single nucleotide difference at the 5'-phosphorylated end, comparing the size of the largest product of the reaction with ssDNA size markers. As shown in Figure 7, the products obtained had sizes of 33 and 34 nucleotides for the 20- and 21-mer gDNA respectively. The localized cutting site in the target was complementary to the +10 and +11 position with respect to the 5 ' end of the gDNA used.

The minimum size of the 5'P-guides was also studied. By shortening the gDNAs at their 3' end and using them in interference

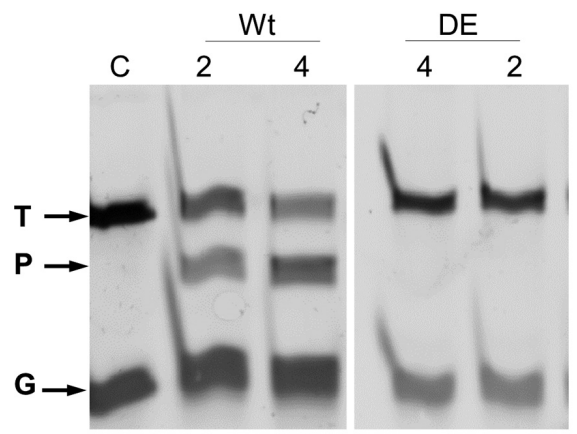

5' -AAACGACGGCCAGTGCCAAGCTTACTATACAACCTACTACCTCAT-3'

3'-TGAtATGtTGGATGATGGAGT-p5'

Figure 2. CbcAgo is active in DNA-DNA interference assays. The wild-type $(\mathrm{Wt})$ and inactive $\mathrm{DE}$ mutant $(\mathrm{DE})$ of the CbcAgo protein were pre-incubated with the indicated 5' phosphorylated guide DNA for 10 min at $37^{\circ} \mathrm{C}$ and further used to cut a complementary 45-nucleotide ssDNA target at the same temperature for $1 \mathrm{~h}$. The reactions were carried out in the presence of 2 or $4 \mathrm{mM} \mathrm{MnCl}$; target $(T)$, guide $(G)$, and the major 34-mer product $(P)$ of the reaction were identified in an $18 \%$ U-PAGE gel.
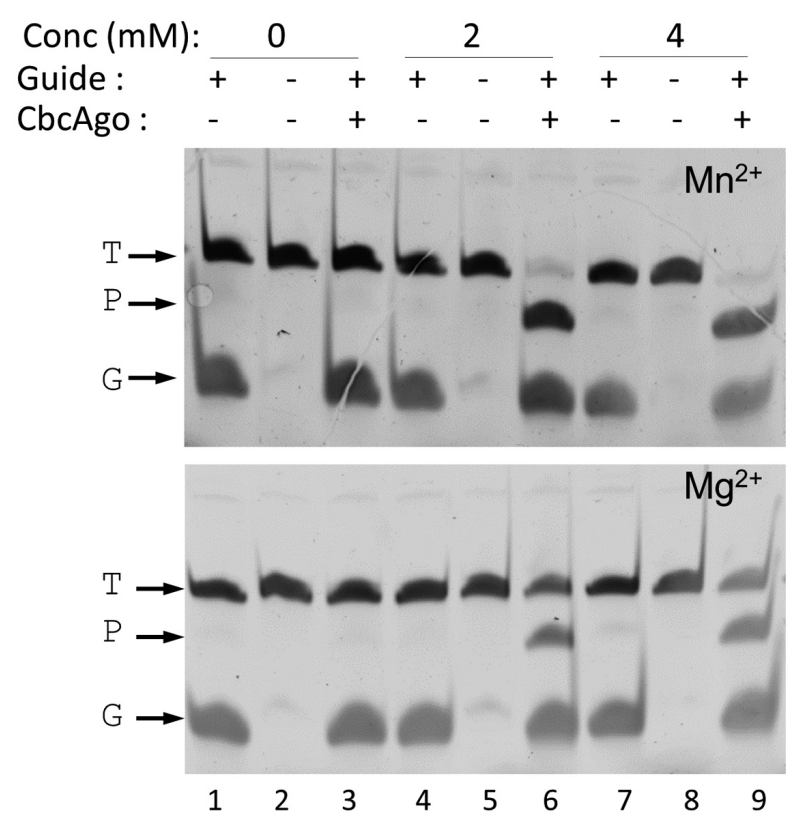

Figure 3. CbcAgo needs divalent cations for activity. CbcAgo was loaded with a 21-mer, 5'-phosphorylated gDNA (G) and incubated with a complementary 45 -mer ssDNA target $(T)$ in reaction buffer in the absence (0) or presence of 2 or $4 \mathrm{mM} \mathrm{Mn}^{2+}$ or $\mathrm{Mg}^{2+}$. The major 34-mer product $(P)$ of the reactions was identified in an $18 \%$ U-PAGE gel; target and guide were the same used in Figure 2.

assays against the same ssDNA target, we found similar efficiencies of cleavage up to a gDNA size of 11 nucleotides (Figure 8). Shorter gDNAs of 9- and even 7-mer still allowed the enzyme to partially cut the ssDNA target. Finally, the ability to direct the enzyme activity towards any desired site within a given ssDNA target was also demonstrated, using different guides of the same size but each with hybridization site displaced by a single base with respect to the next. Despite the fact that different efficiencies were detected, the capability of the guides to direct the wild-type CbcAgo activity against any designed site was clearly shown (Figure 9).

Finally, assays on the activity of CbcAgo on dsDNA were carried out using supercoiled forms of plasmid pMH184 using four different guides complementary to the sense and antisense strands of the hygromycin resistance gene. All the gDNAs used were able to direct the production of a nick in the complementary strand, leading to the generation of open circle forms as the main product (Figure 10). However, using a combination of primers complementary to each strand did not result in the generation of linear forms of the plasmid (not shown).

\section{Discussion}

Novel tools based on CRISPR-Cas9 RNA-DNA interference mechanisms have been developed in the last few years, taking a leading role among the current methods for gene editing. However, significant drawbacks must be overcome in order to allow their safe use in gene therapy, especially off-target actions and putative cellular persistence of the DNA used for the editing process. The description of pAgos in thermophilic bacteria and 


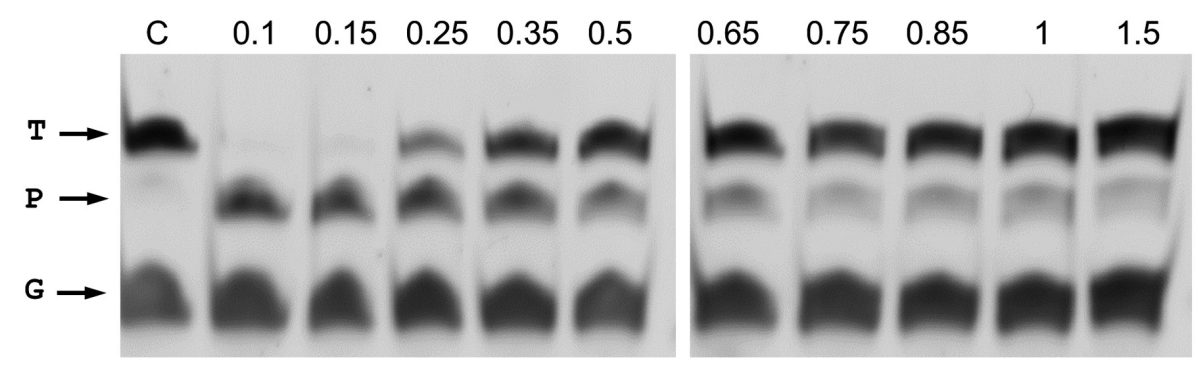

Figure 4. Salt tolerance of CbcAgo. Wild-type CbcAgo was preloaded with the same gDNA used in Figure 2 and incubated with the complementary 45-mer ssDNA target in the presence of the indicated concentrations of $\mathrm{NaCl}(\mathrm{M})$. Target $(\mathrm{T})$, guide $(\mathrm{G})$, and the major 34-mer product $(P)$ of the reaction were identified in an $18 \%$ U-PAGE gel.

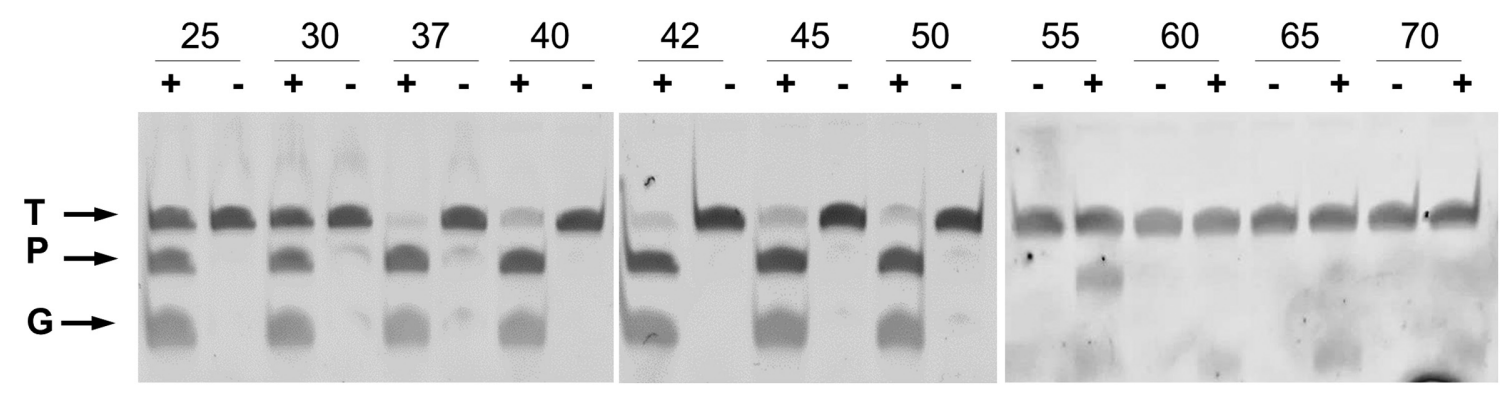

Figure 5. Effect of temperature on CbcAgo. Wild-type CbcAgo was preincubated for 10 min at $37{ }^{\circ} \mathrm{C}$ with (+) or without (-) gDNA and then used in cleavage assays of an ssDNA target for $1 \mathrm{~h}$ at the indicated temperatures. The ssDNA target (T) and gDNA (G) were the same used in Figure 2.

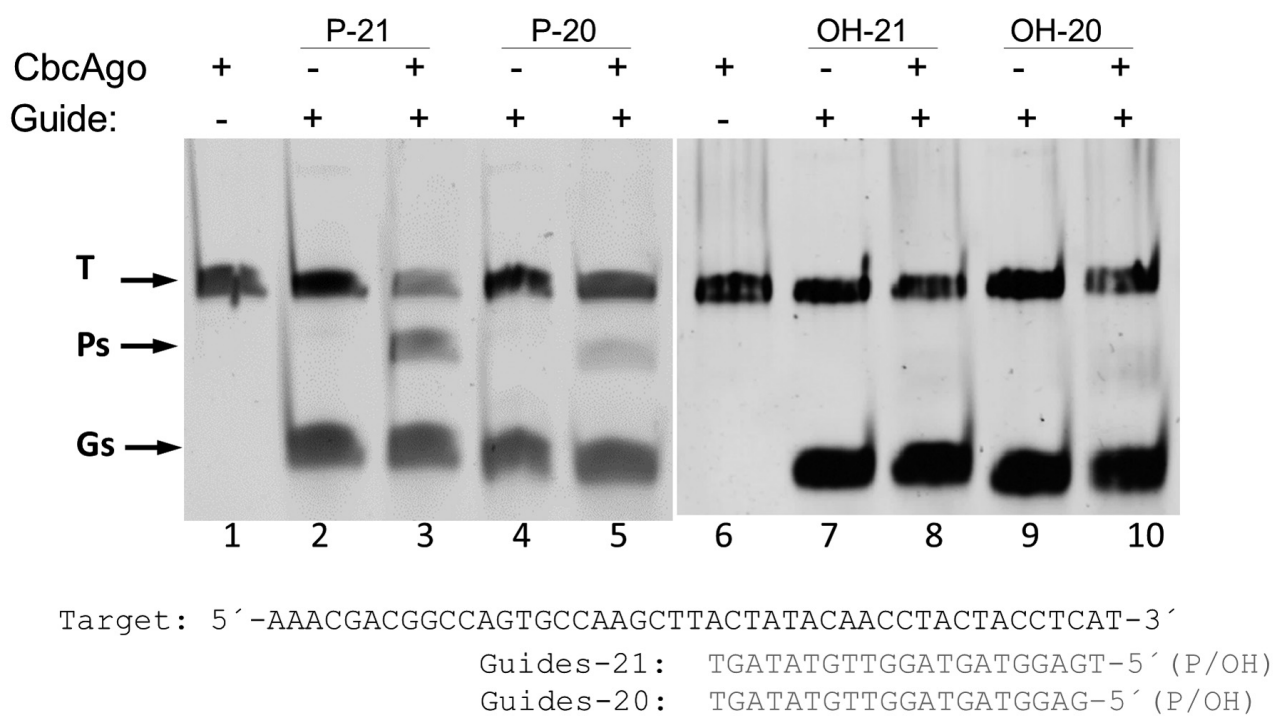

Figure 6. CbcAgo requires 5'-phosphorylated gDNA. The indicated 20- and 21-mer 5'phosphorylated (P) or unphosphorylated (OH) gDNAs were preincubated with CbcAgo and used in interference assays against the same complementary target. Presence (+) or absence $(-)$ of $\mathrm{CbcAgo}$ or gDNA in the reaction are indicated. The target $(\mathrm{T})$, guide $(\mathrm{G})$ and the major 34-mer product $(\mathrm{P})$ of the reaction were identified using an $18 \%$ U-PAGE gel. 


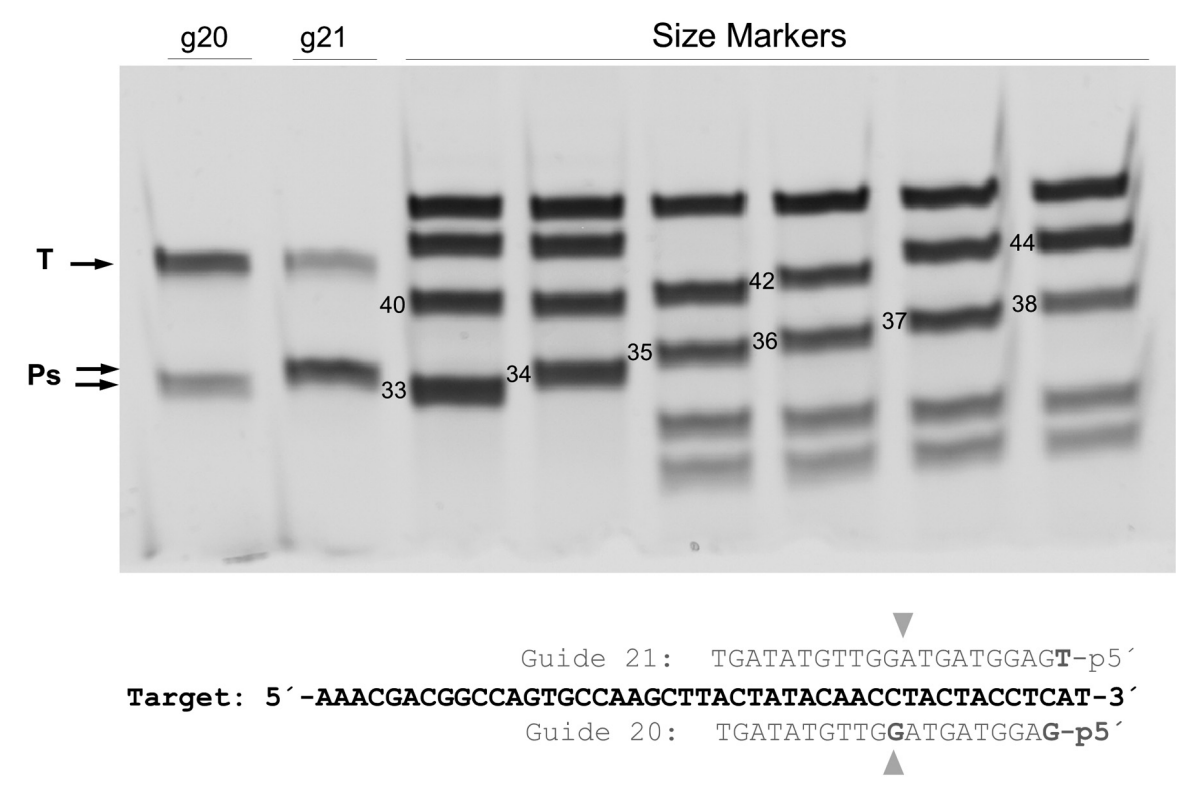

Figure 7. Assessment of the CbcAgo cleavage site. CbcAgo was loaded with 5'-phosphorylated 20- or 21-mer gDNA and used in interference cleavage assays against a 45-mer ssDNA target $(T)$. The sizes of the products $(P)$ were compared with ssDNA standards of the indicated sizes, using a 20\% U-PAGE gel, leading to the conclusion that the cleavage site was complementary to the 10-11 base position of the gDNA.

\section{A}

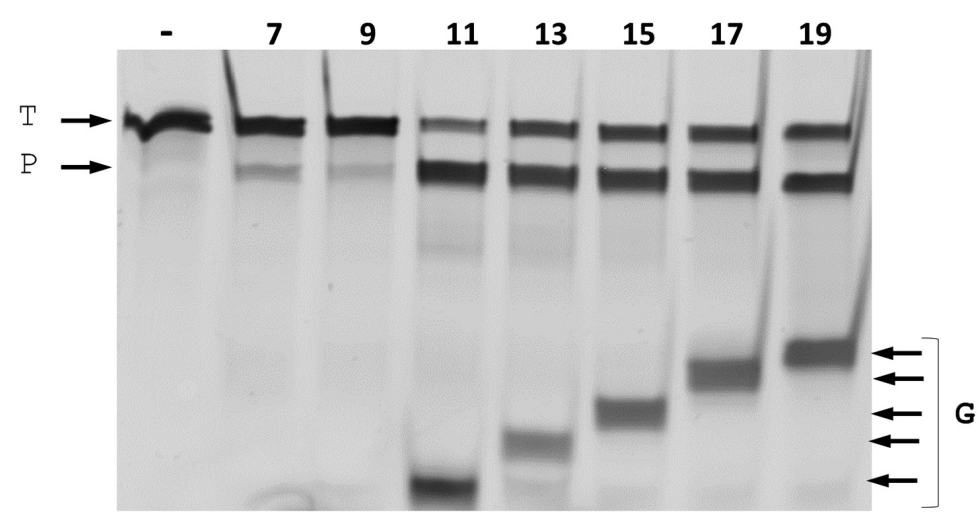

B

5'-GGTCGCGGAGGTtATGGATGCGATCGCTGCGGCCGATCTTAGCCAGACGA-3’

-......................

.................

....................

$\ldots \ldots \ldots \ldots \ldots$.............

$\ldots \ldots \ldots \ldots \ldots$. . . . . .

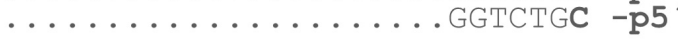

Figure 8. Minimum size of gDNA used by CbcAgo. (A) CbcAgo was incubated with 7-, 9-, 11-, 13-, 15-, 17- or 19-mer gDNAs complementary to a ssDNA target and used them in interference cleavage assays. The target $(T)$, guide $(G)$ and major product $(P)$ of the reaction were identified using an 18\% U-PAGE gel. (B) Sequences of the gDNAs and target ssDNA used in (A). 

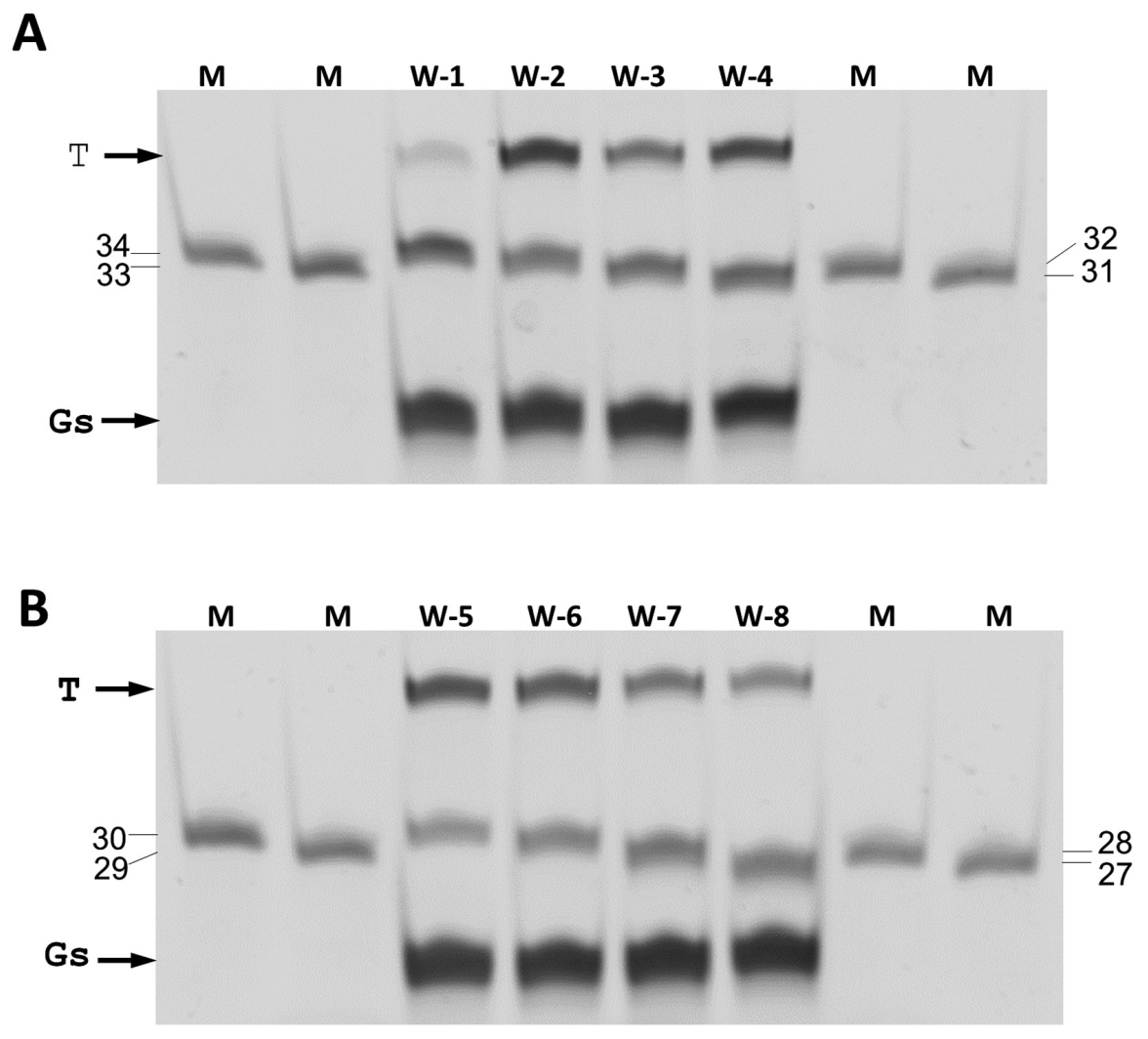

C

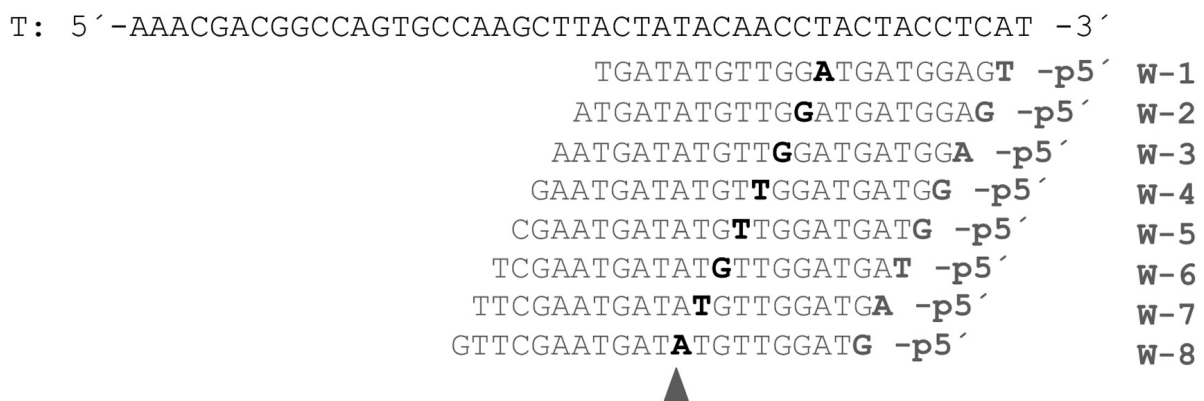

Figure 9. Selection of the cleavage site by CbcAgo. CbcAgo was pre-loaded with a collection of 21-mer, 5'-phosphorylated gDNA that paired at positions displaced by a single nucleotide with a 45-mer ssDNA target $(T)$. The products of the reactions were compared using a 20\% U-PAGE gel with ssDNA markers of the indicated sizes (mer). (A) Assays with w1 to w4 gDNA. (B) Assays with gDNA w-5 to w-8. (C) Target DNA and gDNA used in A and B. Note that the cutting site was displaced along the target by a single nucleotide, always pairing at position 10-11 of the gDNAs (shaded triangle).

archaea that are able to target DNA using ssDNA guides has revealed the possibility of developing a new gene editing tool, in which a mix of the protein and its synthetic gDNA would be enough to produce specific cleavage without leaving anything behind that could produce deleterious long-term effects. This possibility was apparently supported by the publication of an article claiming the use of $\mathrm{NgAgo}$ to modify several genes in mammalian cell cultures ${ }^{12}$. However, the results were not reproducible by any of several groups ${ }^{13}$. For many microbiologists, the use of a protein from a hyperhalophilic archaea was bizarre as they have evolved at the sequence level to tolerate very high potassium chloride concentrations as intracellular 
A

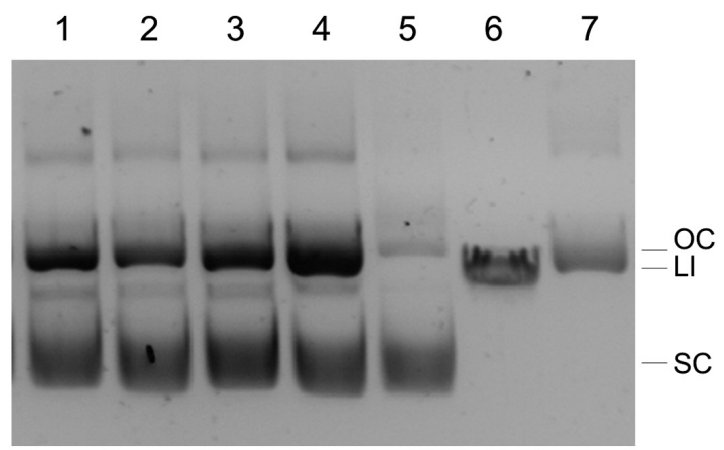

B

\author{
Hygro-2: TCGCTAGCGTAGGTATTGGAGGCGCTGG-p 5 \\ ...5' GGCCGCAGCGATCGCATCCATAACCTCCGCGACCGGTTGCAGAACAGCGGG... 3' \\ Hygro-1: TCGCTAGCGTAGGTATTGGAGGCGCTGG \\ Hygro-4: ${ }^{\prime}{ }^{\prime} \mathrm{p}-\mathrm{T}$ CATCCATAACCTCCGCGACCGGTTGCAG \\ 3' . CCGGCGTCGCTAGCGTAGGTATTGGAGGCGCTGGCCAACGTCTTGTCGCCC...5' \\ Hygro-3: 5 'p-CATCCATAACCTCCGCGACCGGTTGCAG
}

Figure 10. Effects of CbcAgo on dsDNA. (A) CbcAgo was pre-loaded for 15 min at $37^{\circ} \mathrm{C}$ with the Hygro-1 to 4 guides (lanes 1 to 4 ) and incubated for 16 hours at the same temperature with plasmid pMH184 that was essentially supercoiled (lane 5, SC). Linear plasmid (LI) and nicked open circle (OC) were run in lanes 6 and 7 respectively. The molar ratio between CbcAgo:guide:target was $3 \mu \mathrm{M}: 6 \mu \mathrm{M}$ : $0.0074 \mu \mathrm{M}$. Reactions were stopped by adding $100 \mu \mathrm{g} / \mathrm{mL}$ of Proteinase K (Promega) and the products separated in agarose gels. (B) Sequence of the target in plasmid pMH184 paired with the gDNAs used in panel $\mathbf{A}$

compatible solute. Despite this, the article sparked a growing interest in finding an appropriate pAgo protein that could have this function, as thermophilic pAgos have little or no activity at mesophilic temperatures ${ }^{11}$.

In this context, the search for a mesophilic pAgo led our group (and those of J. van der Oost and A.A Aravind) to independently focus on a putative pAgo encoded by Clostridium butyricum due to the mesophilic character of this organism and the presence of the four domains of long pAgos and the catalytic tetrad at its PIWI domain. In a preprint article posted online, the group of J. van der Oost provided an exhaustive description of the CbAgo protein but did not identify the exact strain they used. A further work by Kuzmenko et al. was posted two months later with the in vitro characterization of the same CbAgo. In both articles, further published ${ }^{14,15}$, the same CbAgo protein was used. Although most of the findings of those articles on CbAgo were similar to the properties found for the CbcAgo protein described here, there are also some significant differences that could relate either to the differences found in the sequence of the $\mathrm{CbAgo}$ and $\mathrm{CbcAgo}$ proteins (N188D, D191G, R200K, S204A, E212K, K216N, S217T, E220D, K253N, K258Q, I343V, S466L, being the first position corresponding to the CbAgo and the second to the CbcAgo), to the presence of tags (Strep-tag in CbcAgo, His-tag in
Kuzmenko's CbAgo and no tags in Heddge`s CbAgo), or to the different experimental settings used for their characterization.

Firstly, we detected significant cleavage capacity of ssDNA targets at $55^{\circ} \mathrm{C}$, whereas the CbAgo in the article of Hedgge et al. showed a $50^{\circ} \mathrm{C}$ limit for activity, a temperature at which the CbcAgo was highly active in our work, thus suggesting small thermostability differences between both proteins. However, as in the assays of the article by Kuzmenko et al. also with the CbAgo protein, the nuclease activity was detected even at $60^{\circ} \mathrm{C}$, the apparent differences in thermostability between the three purified proteins are more likely related to the experimental settings than to the presence of amino acid changes or tags in the proteins. The main differences found between CbAgo and CbcAgo were concerning the requirement for 5 ' phosphorylation of the gDNA (Figure 4) and the minimum gDNA size required for efficient cleavage (Figure 5). In our study, the requirement for phosphorylation of the gDNA was quite strict with $\mathrm{CbcAgo}$ and no nuclease activity was detected with any of the 5'-OH gDNAs used in our assays. This result is in agreement with the reported requirements of other pAgos such as ThAgo and PfAgo for gDNA phosphorylation ${ }^{3,4}$, and also with the presence of several contacts between the 5'-P end of the gDNA and specific residues revealed in the structure of $\mathrm{CbAgo}^{14}$. Actually, CbAgo was less active when using 
$5^{\prime} \mathrm{OH}$ guides than when using 5'-P counterparts ${ }^{14}$, and shows exceptionally high affinity to 5-P guides ${ }^{15}$, supporting that the natural gDNA used in vivo for these pAgo are actually 5'-phosphorylated.

Even more surprising was the minimum size of gDNA required for tDNA selection and nuclease activity of CbcAgo, as gDNA of 11 nucleotides were similarly efficient in directing the CbcAgo to the correct target than longer guides, detecting also some activity for gDNAs as short as 7 nucleotides (Figure 8). This contrasts with the minimum 12-mer required for binding of CbAgo to gDNA in single-molecule fluorescence assays and with the minimum 14-mer gDNA needed for cleavage of the ssDNA substrate reported for $\mathrm{CbAgo}^{14,15}$. The reasons for these discrepancies may be partly related to the method of detection used or to the absence of phosphorylation in some of the gDNAs used in the assays with the CbAgo protein ${ }^{14}$. Whatever the case, our data for minimum gDNA requirements is more similar to the 9 nucleotides described for $\mathrm{TtAgo}^{16}$.

Putting our data in the context of the structure for CbAgo described in the article published by the group of J. van der Oost ${ }^{14}$, and in that of $\mathrm{ThAgo}^{6}$ once even small gDNA are attached at a position of the MID domain defined by the gDNA 5'P-residue, CbcAgo is able to scan ssDNA for a matching sequence, approximating paired positions $10-11$ to the active site of the PIWI domain, where the ssDNA target is cleaved in a cation-dependent manner. Smaller 5'-P- guides (i.e. 7-mers) are also efficiently recognized by the MID domain of the protein, which as described in Kuzmenko et al. shows a very high affinity for 5'P guides ${ }^{15}$, and used to screen for complementarity. Once found (at least in an in vitro context without any other competing DNA) these small gDNAs could function as seed to position the tDNA near to the active site of the PIWI domain. Likely through thermodynamic movements, the tDNA eventually reach the catalytic domain in a sort of pendulum movement leading to the observed residual activity. This could be facilitated by the location of the hybridization site for the gDNA at the 3' end of the tDNA, instead of in the middle of the target as in the assays carried out with CbAgo.

Another discrepancy has to do with the effects of CbcAgo on dsDNA. In this study, only nicking activity was detected when supercoiled plasmids were used as substrates and the corresponding gDNA was pre-bound to the protein (Figure 10). In fact, we did not detect any chopping activity with the purified protein in the absence of gDNA, even after 16 hours of incubation at $37^{\circ} \mathrm{C}$. In our assays we did not detect the linearized plasmid form, even when two gDNAs (one for each strand) were used. However, the works with CbAgo detected the double strand break on plasmids at low yields, with the activity being much more efficient in regions with low $\mathrm{G}+\mathrm{C}$ content $^{14,15}$, which could explain the absence of detectable linearization in a higher $\mathrm{G}+\mathrm{C}$ content plasmids such as pMH184 used in our assays. This suggests that the CbcAgo protein alone is unable to open dsDNA of medium to high $\mathrm{G}+\mathrm{C}$ content after its nicking activity and that future directed evolution of the protein will be needed for better adaptation to this type of substrate.

\section{Data availability}

Underlying data

Open Science Framework: Clostridium butyricum CWBI1009 Ago. https://doi.org/10.17605/OSF.IO/8GQUZ ${ }^{17}$

This project contains raw images of the gels used for each figure.

Data are available under the terms of the Creative Commons Zero "No rights reserved" data waiver (CC0 1.0 Public domain dedication).

\section{Acknowledgements}

Technical assistance of E. Sánchez is acknowledged. The professional editing service NB Revisions was used for technical preparation of the text prior to submission.
1. Meister G: Argonaute proteins: functional insights and emerging roles. Nat Rev Genet. 2013; 14(7): 447-459. PubMed Abstract | Publisher Full Text

2. Swarts DC, Makarova $\mathrm{K}$, Wang $\mathrm{Y}$, et al:: The evolutionary journey of Argonaute proteins. Nat Struct Mol Biol. 2014; 21(9): 743-753. PubMed Abstract | Publisher Full Text | Free Full Text

3. Swarts DC, Jore MM, Westra ER, et al.: DNA-guided DNA interference by a prokaryotic Argonaute. Nature. 2014; 507(7491): 258-261. PubMed Abstract | Publisher Full Text | Free Full Text

4. Swarts DC, Hegge JW, Hinojo I, et al:: Argonaute of the archaeon Pyrococcus furiosus is a DNA-guided nuclease that targets cognate DNA. Nucleic Acids Res. 2015; 43(10): 5120-5129.

PubMed Abstract | Publisher Full Text | Free Full Text

5. Zander A, Willkomm S, Ofer S, et al.: Guide-independent DNA cleavage by archaeal Argonaute from Methanocaldococcus jannaschii. Nat Microbiol. 2017 2: 17034 .

PubMed Abstract | Publisher Full Text
6. Yuan YR, Pei Y, Ma JB, et al.: Crystal structure of A. aeolicus argonaute, a sitespecific DNA-guided endoribonuclease, provides insights into RISC-mediated mRNA cleavage. Mol Cell. 2005; 19(3): 405-419. PubMed Abstract | Publisher Full Text | Free Full Text

7. Sunghyeok $\mathrm{Y}$, Taegeun B, Kyoungmi, $\mathrm{K}$, et al:: DNA-dependent RNA cleavage by the Natronobacterium gregoryi Argonaute. bioRxiv. 2017; 1-9. Publisher Full Text

8. Olovnikov I, Chan K, Sachidanandam R, et al.: Bacterial argonaute samples the transcriptome to identify foreign DNA. Mol Cell. 2013; 51(5): 594-605. PubMed Abstract | Publisher Full Text | Free Full Text

9. Sheng G, Zhao H, Wang J, et al:: Structure-based cleavage mechanism of Thermus thermophilus Argonaute DNA guide strand-mediated DNA target cleavage. Proc Natl Acad Sci U S A. 2014; 111(2): 652-657. PubMed Abstract | Publisher Full Text | Free Full Text

10. Swarts DC, Szczepaniak M, Sheng G, et al:: Autonomous Generation and Loading of DNA Guides by Bacterial Argonaute. Mol Cell. 2017; 65(6): 985-998 e986. PubMed Abstract | Publisher Full Text | Free Full Text 
11. Hegge JW, Swarts DC, van der Oost J: Prokaryotic Argonaute proteins: novel genome-editing tools? Nat Rev Microbiol. 2018; 16(1): 5-11. PubMed Abstract | Publisher Full Text

12. Gao $F$, Shen $X Z$, Jiang $F$, et al.: DNA-guided genome editing using the Natronobacterium gregoryi Argonaute. Nat Biotechnol. 2016; 34(7): 768-773. PubMed Abstract | Publisher Full Text

13. Lee $\mathrm{SH}$, Turchiano $\mathrm{G}$, Ata $\mathrm{H}$, et al:: Failure to detect DNA-guided genome editing using Natronobacterium gregoryi Argonaute. Nat Biotechnol. 2016; 35(1): 17-18. PubMed Abstract | Publisher Full Text | Free Full Text

14. Hegge JW, Swarts DC, Chandradoss SD, et al.: DNA-guided DNA cleavage at moderate temperatures by Clostridium butyricum Argonaute. Nucleic Acids
Res. 2019; 47(11): 5809-5821.

PubMed Abstract | Publisher Full Text | Free Full Text

15. Kuzmenko A, Yudin D, Ryazansky S, et al.: Programmable DNA cleavage by Ago nucleases from mesophilic bacteria Clostridium butyricum and Limnothrix rosea. Nucleic Acids Res. 2019; 47(11): 5822-5836.

PubMed Abstract | Publisher Full Text | Free Full Text

16. Wang $\mathrm{Y}$, Sheng $\mathrm{G}$, Juranek $\mathrm{S}$, et al:: Structure of the guide-strand-containing argonaute silencing complex. Nature. 2008; 456(7219): 209-213. PubMed Abstract | Publisher Full Text | Free Full Text

17. Berenguer J: Clostridium butyricum CWBI1009 Ago [Internet]. OSF. 2019. http://www.doi.org/10.17605/OSF.IO/8GQUZ 


\title{
Open Peer Review
}

\section{Current Peer Review Status:}

\section{Version 2}

Reviewer Report 13 January 2020

https://doi.org/10.5256/f1000research.24144.r58429

(C) 2020 Tanner N. This is an open access peer review report distributed under the terms of the Creative Commons Attribution License, which permits unrestricted use, distribution, and reproduction in any medium, provided the original work is properly cited.

\begin{abstract}
Nathan A. Tanner
New England Biolabs, Ipswich, Massachusetts, USA

The authors addressed the major points of criticism from the original submission, with updates and additions to discuss the newer publication and discrepancies with this work. The unusual results and findings at odds with other CbAgo papers are discussed more, adding to the ability of the reader to consider this work in the field. I'd still suggest some different presentation on some of the data figures but the authors disagree and have supplemental versions with fuller images, so this can be attributed to a matter of preference. I feel the revised version is stronger and sufficient for indexing.
\end{abstract}

Competing Interests: No competing interests were disclosed.

Reviewer Expertise: DNA enzymes and polymerases, biochemistry and molecular biology, biotechnology

I confirm that I have read this submission and believe that I have an appropriate level of expertise to confirm that it is of an acceptable scientific standard.

Reviewer Report 10 January 2020

https://doi.org/10.5256/f1000research.24144.r58430

(C) 2020 Santero E et al. This is an open access peer review report distributed under the terms of the Creative Commons Attribution License, which permits unrestricted use, distribution, and reproduction in any medium, provided the original work is properly cited.

Inés Canosa

University Pablo de Olavide, Seville, Spain 


\section{Eduardo Santero}

Andalusian Center for Developmental Biology (CABD), Superior Council of Scientific Investigations (CSIC), Council of Andalusia, Pablo de Olavide University, Seville, Spain

I think authors have satisfactorily dealt with the reviewers comments and, therefore, I have no further comments on the revised version of the manuscript

Competing Interests: No competing interests were disclosed.

Reviewer Expertise: Bacterial Molecular Biology

We confirm that we have read this submission and believe that we have an appropriate level of expertise to confirm that it is of an acceptable scientific standard.

\section{Version 1}

Reviewer Report 02 August 2019

https://doi.org/10.5256/f1000research.20180.r51940

(C) 2019 Tanner N. This is an open access peer review report distributed under the terms of the Creative Commons Attribution License, which permits unrestricted use, distribution, and reproduction in any medium, provided the original work is properly cited.

\section{Nathan A. Tanner}

New England Biolabs, Ipswich, Massachusetts, USA

The study from Garcia-Quintans et al. looks at a new pAgo protein from Clostridium and investigates factors influencing its cleavage activity on DNA substrates. The in vitro activity is characterized pretty well, but there are some serious issues I find with the data and its presentation, as well as the contradictory findings of another recent publication.

1. The authors report a significant (by eye $\sim 40 \%$ ) contaminant of an $\mathrm{N}$-terminal truncation at about half the size of the expected protein (Figure 1). I would assume this is an inactive form of the enzyme, but does it still bind guides? Bind to DNA targets? Perhaps affect the results of all the experiments in the paper? This should be addressed in more detail, and ideally cleaned up (along with the GroEL contaminat) using another chromatography step.

2. Most of the gels are shown as zoomed in cropped sections of the gel. I feel these should instead show the whole, or at least more of, the gel, and include low-molecular weight marker standards. Some gels have oligonucleotide standards but the resolution is very poor in terms of distinguishing between a few bases (I'd suggest moving the guides by more than 1 base). And as shown in Figure 811 ntd ssDNA can clearly be seen, but where is it in the other gels where the product should be 2 ssDNA's? The most problematic is Figure 5 where the far right gel is too poor for publication, and seems to show production of $P$ species without added guide at 55C? Where is the guide in all those wells? Figure 8 seems to 
have additional bands between $P$ and guide, Figure 10 has an unidentified high molecular weight species, and the size markers in Figure 7 should be labeled more clearly.

3. I feel there should be more explanation given to the (to me) bizarre finding that a 7 or 9 base guide can cut at the $+10 / 11$ position... which of course does not have a guided complement. How do the authors think this can happen?

4. The authors mention the Hegge et al., preprint, which they should, but that paper was published in NAR after this study. And importantly, so was another study with CbAgo, from a strain mentioned here (Kuzmenko et al. ${ }^{1}$ ). In this study, the authors show several things at odds with the current work: no cleavage with 10 or 12-base guides even after $24 \mathrm{hr}$ incubation, activity to $60 \mathrm{C}$, ability to use 5 '-OH guides, the ability to cut dsDNA with opposite strand guides at $37 \mathrm{C}$ in 1-4h, and with moderate $(500 \mathrm{nM})$ concentrations of CbAgo a chopping activity on plasmid DNA. It is likely this work was not available at the time the reviewed study was published, but it is difficult to ignore the contradictions now. It is possible that the $\mathrm{Cb} / \mathrm{CbcAgo}$ protein is exactly the same in all 3 studies, and these discrepancies are significant for the conclusions presented here.

5. Related, I'd expect there to be some plasmid chopping given the time and concentrations the authors describe. But no Apo reactions are shown in Figure 10, an important control that is left out. And a comparison of attempts to digest non-supercoiled plasmid would be good for the explanation that dsDNA cannot be accessed w/o supercoiling.

6. Minor points, but there are some errors ("xilencyanol", "ImajeJ) and inconsistencies (PfAgo/PfuAgo) that should be fixed.

\section{References}

1. Kuzmenko A, Yudin D, Ryazansky S, Kulbachinskiy A, et al.: Programmable DNA cleavage by Ago nucleases from mesophilic bacteria Clostridium butyricum and Limnothrix rosea.Nucleic Acids Res. 2019; 47 (11): 5822-5836 PubMed Abstract | Publisher Full Text

Is the work clearly and accurately presented and does it cite the current literature? Partly

Is the study design appropriate and is the work technically sound? Partly

Are sufficient details of methods and analysis provided to allow replication by others? Yes

If applicable, is the statistical analysis and its interpretation appropriate? Not applicable

Are all the source data underlying the results available to ensure full reproducibility? No source data required

Are the conclusions drawn adequately supported by the results? 
Partly

Competing Interests: No competing interests were disclosed.

Reviewer Expertise: DNA enzymes and polymerases, biochemistry and molecular biology, biotechnology

I confirm that I have read this submission and believe that I have an appropriate level of expertise to confirm that it is of an acceptable scientific standard, however I have significant reservations, as outlined above.

Author Response 23 Dec 2019

Jose Berenguer, Universidad Autónoma de Madrid-Consejo Superior de Investigaciones Científicas, Madrid, Spain

\section{Reviewer 2}

García-Quintans et al. reports on the identification of an Argonaute protein coding gene from the mesophilic bacterium Clostridium butyricum strain CWBI 1009, and characterise its product as a potential genome editing tool alternative to the well-known CRISPR/Cas.

Authors have purified the native protein and an inactive variant as a control, and thoroughly characterise its activity in relation to a number of parameters such as different temperatures, cations and ionic strength. Altogether, the work of García-Quintans is a welldesigned characterisation of the in vitro activity of the CbcAgo protein.

A similar work has been recently published in Nucleic Acids Research1, by the group of John van der Oost using a similar CbAgo protein from an unspecified strain of C. butyricum, as acknowledged by the authors. It appears that both proteins have very similar characteristics.

The authors claim some relevant differences between both proteins:

Enzyme stability at different temperatures: In first place, none of authors assay thermostability, they assay activity at different temperatures, which is not the same. This should be changed in the Discussion, pg. 10. Based on the partial activity detected at $55^{\circ} \mathrm{C}$ in this paper, authors claim CbcAgo might be more "stable" than CbAgo (Discussion, pg. 10). However, $\mathrm{CbAgo}$ activity was not assayed at $55^{\circ} \mathrm{C}$ but at $50^{\circ} \mathrm{C}$ (partially active) and $64^{\circ} \mathrm{C}$ (inactive). A comparison of the activities at the same temperature, $50^{\circ} \mathrm{C}$, which show almost maximal activity of $\mathrm{CbcAgo}$ but substantially reduced activity of $\mathrm{CbAgo}(<50 \%)$, would be more reliable. Anyways, since the difference is very small, it is very difficult to ascertain whether the differences are real or a consequence of slightly different assay conditions. Answer:

In a further article by Kuzmenko et all, the CbAgo protein shows nuclease activity up to $60^{\circ} \mathrm{C}$, so the apparent thermostability differences are more likely due to the experimental settings used than to the protein sequence itself. We have modified the discussion accordingly just saying that the apparent activity at high temperature is higher under our experimental conditions, but that due to differences in the assays (dDNA and tDNA) the data cannot be directly compared

Strict dependence on phosphorylation: Both $\mathrm{CbAgo}$ and $\mathrm{CbcAgo}$, were unable to cut a short 45-mer target DNA if the gDNA is 5'-OH. However, Hegge et al., 20191, additionally 
reported partial activity of CbAgo on a longer target (120-mer), which was not tested in this manuscript. Therefore, in this regard, there is no data that supports the difference between both proteins claimed in this manuscript.

Answer:

This has been already commented as answer to point 4 raised by reviewer 1 . We agree in that even for the CbAgo it is more likely to use a 5'P gDNA than an 5'-OH one, as i) they are less active in the best of the cases than 5'-P counterparts, and ii) the binding site at the MID domain shows several contacts between the 5'P extreme of the gDNA and residues in the protein, supporting a higher affinity for this type of substrates than for $5^{\prime} \mathrm{OH}$ ones. The differences found are more likely due to differences in the experimental setting, including the selection of the substrates and the hybridization position.

Minimum size length of the gDNA: By comparing the results obtained with both proteins, it is apparent that CbcArgo requires a shorter gDNA to cleave the target. I think this is the most evident difference. However, as the authors acknowledge, these differences may be due to technical reasons rather than a difference in catalytic activity between the Argo proteins. The question of whether CbcArgo and CbArgo show any difference in activity could only be solved by making a side by side comparison of both proteins having the same tag, and using exactly the same procedure.

Anyways, I really miss an alignment of $\mathrm{CbAgo}$ and $\mathrm{CbcAgo}$ proteins to know how different these proteins are at the amino acid level.

Answer:

Proteins CbAgo (used in the articles of Hedgge et al and Kuzmenko et al and CbcAgo (Used in this article) are very similar. From the 748 amino acids of the three protein only 12 differences exist: N188D, D191G, R200K, S204A, E212K, K216N, S217T, E220D, K253N, K258Q, I343V, S466L, being the first position corresponding to the CbAgo and the second to the CbcAgo. These changes are located mainly at inter-domain regions and could be not too relevant for the activity but could affect parameters such as stability. Additional differences in the results between both proteins could be due to the presence or absence of tags (Strep-tag in CbcAgo, His-tag in Kuzmenko's CbAgo and no tags in Heddge's CbAgo).

Other comments:

Please, properly align lanes and lanes names/numbers in Fig. 1.

Answer:

OK, done

Requirement for 5'phosphorylated gDNA is shown in Fig. 6, not 4 (Discussion, pg. 10). Answer:

OK, Modified

Answer:

Actualized references included in the text:

Hegge, J. W. et al. DNA-guided DNA cleavage at moderate temperatures by Clostridium butyricum Argonaute. Nucleic Acids Res. 47, 5809-5821. doi: 10.1093/nar/gkz306.(2019).

Kuzmenko, A., Yudin, D., Ryazansky, Kulbachinskiy, S. A. \& Aravin, A. A. Programmable DNA cleavage by Ago nucleases from mesophilic bacteria Clostridium butyricum and Limnothrix rose. Nucleic Acids Res. 47, 5822-5836 doi: 10.1093/nar/gkz379 (2019) 
Competing Interests: No competing interst to report

Reviewer Report 30 July 2019

https://doi.org/10.5256/f1000research.20180.r51304

(C) 2019 Santero E et al. This is an open access peer review report distributed under the terms of the Creative Commons Attribution License, which permits unrestricted use, distribution, and reproduction in any medium, provided the original work is properly cited.

\section{Eduardo Santero}

Andalusian Center for Developmental Biology (CABD), Superior Council of Scientific Investigations (CSIC), Council of Andalusia, Pablo de Olavide University, Seville, Spain

\section{Inés Canosa}

University Pablo de Olavide, Seville, Spain

García-Quintans et al. reports on the identification of an Argonaute protein coding gene from the mesophilic bacterium Clostridium butyricum strain CWBI 1009, and characterise its product as a potential genome editing tool alternative to the well known CRISPR/Cas. Authors have purified the native protein and an inactive variant as a control, and thoroughly characterise its activity in relation to a number of parameters such as different temperatures, cations and ionic strength. Altogether, the work of García-Quintans is a well-designed characterisation of the in vitro activity of the CbcAgo protein.

A similar work has been recently published in Nucleic Acids Research ${ }^{1}$, by the group of John van der Oost using a similar CbAgo protein from an unspecified strain of $C$. butyricum, as acknowledged by the authors. It appears that both proteins have very similar characteristics.

The authors claim some relevant differences between both proteins:

Enzyme stability at different temperatures: In first place, none of authors assay thermostability, they assay activity at different temperatures, which is not the same. This should be changed in the Discussion, pg. 10. Based on the partial activity detected at $55^{\circ} \mathrm{C}$ in this paper, authors claim CbcAgo might be more "stable" than CbAgo (Discussion, pg. 10). However, CbAgo activity was not assayed at $55^{\circ} \mathrm{C}$ but at $50^{\circ} \mathrm{C}$ (partially active) and $64^{\circ} \mathrm{C}$ (inactive). A comparison of the activities at the same temperature, $50^{\circ} \mathrm{C}$, which show almost maximal activity of CbcAgo but substantially reduced activity of $\mathrm{CbAgo}(<50 \%)$, would be more reliable. Anyways, since the difference is very small, it is very difficult to ascertain whether the differences are real or a consequence of slightly different assay conditions.

Strict dependence on phosphorylation: Both $\mathrm{CbAgo}$ and $\mathrm{CbcAgo}$, were unable to cut a short 45mer target DNA if the gDNA is 5'-OH. However, Hegge et al., 2019'1, additionally reported partial activity of CbAgo on a longer target (120-mer), which was not tested in this manuscript. Therefore, 
in this regard, there is no data that supports the difference between both proteins claimed in this manuscript.

Minimum size length of the gDNA: By comparing the results obtained with both proteins, it is apparent that CbcArgo requires a shorter gDNA to cleave the target. I think this is the most evident difference. However, as the authors acknowledge, these differences may be due to technical reasons rather than a difference in catalytic activity between the Argo proteins. The question of whether CbcArgo and CbArgo show any difference in activity could only be solved by making a side by side comparison of both proteins having the same tag, and using exactly the same procedure.

Anyways, I really miss an alignment of CbArgo and CbcArgo proteins to know how different these proteins are at the amino acid level.

Other comments:

Please, properly align lanes and lanes names/numbers in Fig. 1.

Requirement for 5'phosphorylated gDNA is shown in Fig. 6, not 4 (Discussion, pg. 10).

\section{References}

1. Hegge JW, Swarts DC, Chandradoss SD, Cui TJ, et al.: DNA-guided DNA cleavage at moderate temperatures by Clostridium butyricum Argonaute.Nucleic Acids Res. 2019; 47 (11): 5809-5821

PubMed Abstract | Publisher Full Text

Is the work clearly and accurately presented and does it cite the current literature? Yes

Is the study design appropriate and is the work technically sound?

Yes

Are sufficient details of methods and analysis provided to allow replication by others? Yes

If applicable, is the statistical analysis and its interpretation appropriate? Yes

Are all the source data underlying the results available to ensure full reproducibility? Yes

Are the conclusions drawn adequately supported by the results? Partly

Competing Interests: No competing interests were disclosed.

Reviewer Expertise: Bacterial Molecular Biology

We confirm that we have read this submission and believe that we have an appropriate level of expertise to confirm that it is of an acceptable scientific standard, however we have 


\section{significant reservations, as outlined above.}

Author Response 23 Dec 2019

Jose Berenguer, Universidad Autónoma de Madrid-Consejo Superior de Investigaciones Científicas, Madrid, Spain

\section{Reviewer 1.}

The study from Garcia-Quintans et al. looks at a new pAgo protein from Clostridium and investigates factors influencing its cleavage activity on DNA substrates. The in vitro activity is characterized pretty well, but there are some serious issues I find with the data and its presentation, as well as the contradictory findings of another recent publication.

1. The authors report a significant (by eye $\sim 40 \%$ ) contaminant of an $\mathrm{N}$-terminal truncation at about half the size of the expected protein (Figure 1). I would assume this is an inactive form of the enzyme, but does it still bind guides? Bind to DNA targets? Perhaps affect the results of all the experiments in the paper? This should be addressed in more detail, and ideally cleaned up (along with the GroEL contaminat) using another chromatography step.

Answer:

As described in the article these contaminant proteins were systematically associated to the full length protein. The use of an inactive mutant cbAgo in which the $\mathrm{N}$-terminal truncated fragment and the GroEL proteins were also co-purified guarantees that the observed activity on the target DNA in the presence of gDNA is exclusively due to the catalytic activity of the wt enzyme and not the result of hidden activity of the co-purified proteins. A series of different chromatographic steps have been tried, and in all cases separation of contaminants was not possible and/or the activity of the enzyme was diminished However we agree in that N-terminal fragment could bind either target or gDNA, leading to a minor subestimation of the actual activity of the enzyme or the optimal ratio target:gDNA, but without affecting the conclusions shown in the article.

2. Most of the gels are shown as zoomed in cropped sections of the gel. I feel these should instead show the whole, or at least more of, the gel, and include low-molecular weight marker standards. Some gels have oligonucleotide standards but the resolution is very poor in terms of distinguishing between a few bases (I'd suggest moving the guides by more than 1 base). And as shown in Figure $811 \mathrm{ntd}$ ssDNA can clearly be seen, but where is it in the other gels where the product should be 2 ssDNA's? The most problematic is Figure 5 where the far right gel is too poor for publication, and seems to show production of $P$ species without added guide at 55C? Where is the guide in all those wells? Figure 8 seems to have additional bands between $P$ and guide, Figure 10 has an unidentified high molecular weight species, and the size markers in Figure 7 should be labeled more clearly. Answer:

Due to requirements for organizing easy-to-follow figures, the images are cropped, as most figures in articles in the field are. However, as described in the article, the original full size images of all the gels used are accessible for detailed analysis at https://doi.org/10.17605/OSF.IO/8GQUZ

Regarding gel resolution, we do not agree with the reviewer. Under the conditions used a single base makes a difference in the detected mobility of the gDNA and products, and our interest of using base-to-base changes was to be sure that we were able to move the cutting site in the 
tDNA in a precise manner (i.e. figs 7, 9). As there are so many size markers, only those closer to the size of the products were indicated, but likely the size of the numbers is too small for readers and are increased in the revised version.

Regarding Fig 8, as the reviewer comments the reaction generates two SSDNA products from the tDNA. The largest one is 40 mer and is detected and labelled as $P$ in the figures, and this is also the most adequate fragment for comparison. The small one is only 10 mer long (at the 3' extreme of the tDNA) and escapes from the standard gels (lane 11 in Fig 8 shows the 11mer gDNA at the bottom of the gel). Also, in the other figures the small tDNA product moves out of the gels due to its small size.

In figure 8, the reviewer points to the presence of minor bands below the main 40 mer product, especially under the lanes labelled 11 and 13. We cannot be sure of their origin but could correspond to lower affinity matches of the guides (11 and 13 mer) with the tDNA, as they are not detected with longer guides.

Regarding figure 5, the reviewer is right. The line indicating absence (-) or presence (+) of guides have contracted during the figure assembly and it apparently seems that the enzyme cuts without guide at 50 and $55^{\circ} \mathrm{C}$, but it is not that way. In the gel at right, the left lanes below each temperature $\left(55,60,65\right.$ and $\left.70^{\circ} \mathrm{C}\right)$ corresponds to assays without gDNA and the right one with gDNA (detected at the gel bottom), whereas in the left and central panels is first with (+) and then without (-). In all cases, the product is only detected when the guide is present. This figure will be modified to correct the alignment of the labellings.

Respect to Fig. 10, the high molecular size species detected could be concatenated plasmids, as it was detected in the untreated plasmid preparation (lane 5) and in the open circle treatment (lane 7) but not in the linear form (lane 6).

3. I feel there should be more explanation given to the (to me) bizarre finding that a 7 or 9 base guide can cut at the $+10 / 11$ position... which of course does not have a guided complement. How do the authors think this can happen?

Answer:

As the reviewer comments the ability of CbAgo to cut with low efficiency tDNA using guides so small that their 3' end do not reach the catalytic residue in the protein where the cut is carried out was a surprising feature (at least 11 mer pairing would be needed as deduced from the structure in Hedge et al). Under our experimental conditions 5'-phosphorilated guides of 11 or more nucleotides are very efficient triggering the enzyme activity at complementary 10/11 position of the tDNA (Fig. 8). Smaller P-guides of 9 and even of 7 mer are still able to direct the enzyme to the expected cutting site, but with much lesser efficiency (Fig 8). The explanation that we find for this is that the small 5'-P-guides are also efficiently recognized by the MID domain of the protein and used to screen for complementarity. Once found (in a context without any other competing DNA) these small gDNAs could function as seed to position the tDNA near to the active site of the PIWI domain. Likely through thermodynamic movements, the target DNA eventually reach the catalytic domain in a sort of pendulum movement leading to the observed residual activity. This explanation has been included in the text for clarification

4. The authors mention the Hegge at al., preprint, which they should, but that paper was published in NAR after this study. And importantly, so was another study with CbAgo, from a strain mentioned here (Kuzmenko et al). In this study, the authors show several things at odds with the current work: no cleavage with 10 or 12 -base guides even after $24 \mathrm{hr}$ 
incubation, activity to $60 \mathrm{C}$, ability to use 5'-OH guides, the ability to cut dsDNA with opposite strand guides at $37 \mathrm{C}$ in $1-4 \mathrm{~h}$, and with moderate $(500 \mathrm{nM})$ concentrations of CbAgo a chopping activity on plasmid DNA. It is likely this work was not available at the time the reviewed study was published, but it is difficult to ignore the contradictions now. It is possible that the $\mathrm{Cb} / \mathrm{CbcAgo}$ protein is exactly the same in all 3 studies, and these discrepancies are significant for the conclusions presented here.

Answer:

As the reviewer indicates the article preprint by Kuzmenko was not available when the present article was sent for publication. The revised version includes the actual publication of both articles by Hegge et al and Kuzmenko et al in Nucleic Acids Research, both dealing with the same version of the CbAgo protein.

The main discrepancies between our work and those mentioned above (which also show discrepancies between them) are the minimum size of the guides required for efficient cutting, smaller in our work, and the requirement for 5'-phosphorilation of our guides for efficient activity, and both are likely related.

Phosphorilation of the guides: In the referred articles the use of 5'OH-gDNA under their experimental conditions allows the cutting of tDNA by CbAgo at lower efficiency than with phosphorylated guides (actually suggesting that the natural function for these proteins could require phosphorylated guides), whereas under our experimental conditions the CbcAgo protein was basically inactive at using 5' OH-guides of 20 and 21 mer compared to the phosphorylated ones. The reasons underlying this difference could be related differnte and likely concurrent experimental differences. First, our gDNA hibridizes at the 3' extreme of the tDNA instead of acting in the middle of the target as in Kuzmenko et al. Second, the size of the tDNA could also have an effect, as suggested by supplementary figure 4 of the article by Hegge et al in which a $5^{\prime} \mathrm{OH}$ guide does not cut a 45 mer target (identical in size to that used in our experiments), whereas it functions with a tDNA of 120 mer. Third, differences in the sequence of the CbAgo (used in Heddge and Kuzmenco works) and CbcAgo proteins (12 amino acid positions) or in their affinity taggings (Strep-tag in our work, His-tag in Kuzmenko's and no tags in Heddge) could have effects on their performance. In any case, as commented above preference for $5^{\prime} P$ guides for CbcAgo is clear in all the cases, and could be significant regarding its actual function in a cell context.

Minimum size of the guides: The preference for 5'P guides by CbcAgo under our experimental conditions could also be the basis for experimental discrepancies regarding the minimum guide size to direct the protein, as in our experiments all our guides were phosphorilated, whereas in the works of Heddge et al the guides are labelled with a large fluorophore (Cy3), and in that of Kuzmenko et al. the guides hybridize in the middle of larger tDNA instead of pairing starting at the $3^{\prime}$ extreme of the tDNAs as we did in our experimental setting.

DNA chopping: Another point raised by the reviewer focus on the so called "chopping" activity of the enzyme on double stranded DNA. In our hands, we did not observe any degradative activity on the plasmid used as target (PMH184) even after 16 hours of incubation at $37^{\circ} \mathrm{C}$ with significant concentrations of CbAgo protein loaded with gDNA (Fig 10) or without gDNA (experiment not shown).

dsDNA activity: Regarding cutting of supercoiled plasmid, it seems clear that nicks were generated using CbcAgo loaded with guides directed to both DNA strands of a supercoiled plasmid, but under our experimental condition we did not detect linearized plasmid, supporting interference between overlapping cutting sites 
5. Related, I'd expect there to be some plasmid chopping given the time and concentrations the authors describe. But no Apo reactions are shown in Figure 10, an important control that is left out. And a comparison of attempts to digest non-supercoiled plasmid would be good for the explanation that dsDNA cannot be accessed w/o supercoiling.

Answer:

As commented above, no chopping was detected in our experiments despite incubation for $16 \mathrm{~h}$ at $37^{\circ} \mathrm{C}$ with the protein in nmolar ratios $10: 1$ with the dsDNA plasmid

6. Minor points, but there are some errors ("xilencyanol", "ImajeJ) and inconsistencies (PfAgo/PfuAgo) that should be fixed.

Answer:

Corrected in the revised form

Competing Interests: No competing interest

The benefits of publishing with F1000Research:

- Your article is published within days, with no editorial bias

- You can publish traditional articles, null/negative results, case reports, data notes and more

- The peer review process is transparent and collaborative

- Your article is indexed in PubMed after passing peer review

- Dedicated customer support at every stage

For pre-submission enquiries, contact research@f1000.com 